\title{
Contributions of Heating and Forcing to the High-Latitude Lower Thermosphere: Dependence on the Interplanetary Magnetic Field
}

\author{
Young-Sil Kwak ${ }^{1 \dagger}$, Arthur Richmond ${ }^{2}$, Byung-Ho $\mathrm{Ahn}^{3}$, and Kyung-Suk Cho ${ }^{1}$ \\ ${ }^{1}$ Solar and Space Weather Research Group, Korea Astronomy and Space Science Institute, Daejeon 305-348, Korea \\ ${ }^{2}$ High Altitude Observatory, National Center for Atmospheric Research, Boulder, CO 80301, USA \\ ${ }^{3}$ Department of Earth Science, Kyungpook National University, Daegu 702-701, Korea
}

To better understand the physical processes that maintain the high-latitude lower thermospheric dynamics, we have identified relative contributions of the momentum forcing and the heating to the high-latitude lower thermospheric winds depending on the interplanetary magnetic field (IMF) and altitude. For this study, we performed a term analysis of the potential vorticity equation for the high-latitude neutral wind field in the lower thermosphere during the southern summertime for different IMF conditions, with the aid of the National Center for Atmospheric Research ThermosphereIonosphere Electrodynamics General Circulation Model (NCAR-TIEGCM). Difference potential vorticity forcing and heating terms, obtained by subtracting values with zero IMF from those with non-zero IMF, are influenced by the IMF conditions. The difference forcing is more significant for strong IMF $B_{y}$ condition than for strong IMF $B_{z}$ condition. For negative or positive $B_{y}$ conditions, the difference forcings in the polar cap are larger by a factor of about 2 than those in the auroral region. The difference heating is the most significant for negative IMF $B_{z}$ condition, and the difference heatings in the auroral region are larger by a factor of about 1.5 than those in the polar cap region. The magnitudes of the difference forcing and heating decrease rapidly with descending altitudes. It is confirmed that the contribution of the forcing to the high-latitude lower thermospheric dynamics is stronger than the contribution of the heating to it. Especially, it is obvious that the contribution of the forcing to the dynamics is much larger in the polar cap region than in the auroral region and at higher altitude than at lower altitude. It is evident that when $B_{z}$ is negative condition the contribution of the forcing is the lowest and the contribution of the heating is the highest among the different IMF conditions.

Keywords: high-latitude lower thermosphere, Interplanetary magnetic field, forcing, heating

\section{INTRODUCTION}

At high latitudes the thermospheric dynamics are governed by various heat and momentum sources: non-uniform solar heating, atmospheric tides and other waves coming from below, and energy and momentum sources associated with magnetosphere-ionosphere coupling, such as the magnetospheric convective electric field and the precipitation of energetic electrons and ions into the auroral regions.
Recently several modeling studies have been attempted to understand the physical process that control the high-latitude lower thermospheric dynamics. Kwak \& Richmond (2007) studied the momentum forcing balance that are mainly responsible for maintaining the high-latitude lower thermospheric wind system by using the National Center for Atmospheric Research Thermosphere-Ionosphere Electrodynamics General Circulation Model (NCAR-TIEGCM). Kwak et al. (2008b) analyzed the divergence and vorticity of the high-latitude neutral (c) This is an Open Access article distributed under the terms of the Creative Commons Attribution Non-Commercial License (http://creativecommons.org/licenses/by-nc/3.0/) which permits unrestricted non-commercial use, distribution, and reproduction in any medium, provided the original work is properly cited.
Received Jul 28, 2010 Revised Aug 20, 2010 Accepted Aug 26, 2010 ${ }^{\dagger}$ Corresponding Author

E-mail: yskwak@kasi.re.kr

Tel: +82-42-865-2039 Fax: +82-42-865-2020 
wind field in the lower thermosphere during the southern summertime. They showed that the mean neutral wind pattern in the high-latitude lower thermosphere is dominated by rotational flow rather than by divergence flow. Kwak et al. (2008a) performed a term analysis of vorticity equation that describes the driving forces for the rotational component of the horizontal wind in order to determine key processes that causes strong rotational flow in the high-latitude lower thermospheric winds.

We have extended previous works by Kwak \& Richmond (2007) and Kwak et al. (2007, 2008a,b), which have been attempted to better understand the physical process maintaining thermospheric dynamics at high latitudes, and here first perform a "term analysis of the potential vorticity equation" for the high-latitude neutral wind field in the lower thermosphere. These analyses can provide separate insight into the relative strength of the momentum forcing and the heating responsible for driving winds at the high-latitude lower thermosphere. The momentum forcing is associated with the viscous force and drag force from convecting ions. The heating is the net heat including the heat transfer by downward molecular and eddy heat conduction, the absorption of solar ultraviolet (UV) and extreme ultraviolet (EUV) radiation, auroral heating by particles, Joule dissipation of ionospheric currents, release of chemical energy by the atomic oxygen recombination, and radiative $\mathrm{CO}_{2}, \mathrm{NO}$ and $O$ infrared emissions.

It is known that high-latitude ionospheric plasma convection and current depend on the direction of the interplanetary magnetic field (IMF) (e.g., Heppner 1972, Foster et al. 1986, Heppner \& Maynard 1987, Ruohoniemi \& Greenwald 1996, Weimer 1995, 2001). Thus the highlatitude thermospheric wind which are influenced by interaction with the ionospheric plasma, forcing on the wind and Joule/particle heating, are also strongly modulated by the IMF variation (e.g., McCormac \& Smith 1984, McCormac et al. 1985, 1991, Killeen et al. 1985, 1995, Meriwether \& Shih 1987, Thayer et al. 1987, Rees \& Fuller-Rowell 1989, 1990, Sica et al. 1989, Hernandez et al. 1991, Niciejewski et al. 1992, 1994, Won 1994, Richmond et al. 2003, McHarg et al. 2005, Zhang et al. 2005, Kwak \& Richmond 2007, Kwak et al. 2007). That is, one can expect there is an intimate relationship between the IMF variation and the relative strength of momentum forcing / heating responsible for maintaining thermospheric dynamics at high latitudes. In this study, we investigate the relative contributions of the momentum forcing and the heating to the high-latitude lower thermospheric dynamics depending on the IMF during the southern sum- mertime by using NCAR-TIEGCM.

\section{MODEL}

The NCAR-TIEGCM used in this study computes selfconsistently the coupled thermospheric/ ionospheric dynamics, the associated dynamo electric fields and currents, and the electrodynamic feedback on the neutral and plasma motions and thermodynamics (Richmond et al. 1992). The nonlinear primitive equations for momentum, energy, continuity, hydrostatics, current density, and the equations of state are solved for the neutrals and the ions. The model calculates global distributions of neutral gas temperature, wind, mass mixing ratios of the major constituents $\mathrm{O}_{2}, N_{2}$, and $O$, and of the minor constituents $N\left({ }^{2} D\right), N\left({ }^{4} S\right)$ and $N O$. The Eulerian model of the ionosphere solves for global distributions of electron and ion temperatures and number densities of $\mathrm{O}^{+}, \mathrm{O}_{2}^{+}, \mathrm{NO}^{+}$, $\mathrm{N}_{2}^{+}$, and $\mathrm{N}^{+}$. The TIEGCM has a $5^{\circ}$ latitude-by-longitude grid. The vertical coordinate of the model consists of 29 constant pressure levels ranging from approximately 97 $\mathrm{km}$ to $500 \mathrm{~km}$ in altitude, with a vertical resolution of 2 grid points per scale height. In this study we focus on altitudes up to about $200 \mathrm{~km}$. The external inputs required by the model are the solar EUV and UV fluxes, the auroral particle precipitation, the ionospheric convection pattern at high latitudes, and the upward propagating tides from the middle atmosphere.

We analyze the relative contributions of the momentum forcing and the heating to the high-latitude lower thermospheric dynamics for different IMF directions, for seasonal and solar conditions representative of 1993 January 23. This period is a characteristic of conditions for wind observations analyzed by Richmond et al. (2003) and previous analyses of forcing (Kwak \& Richmond 2007, Kwak et al. 2007) and vorticity (Kwak et al. 2008a,b). On this date, the daily F10.7 index was recorded as 102.7 $\times 10^{-22} \mathrm{~W} / \mathrm{m}^{2} / \mathrm{Hz}$. The total hemispheric power (HP) was used to specify the high-latitude auroral particle precipitation pattern and is related with the Kp index by HP (in gigawatts $)=-2.78+9.33 \times K p$ (Maeda et al. 1989) . The mean $K p$ index on January 23, 1993 was 1, although the actual time-varying values for this date were used. The empirical electric potential model by Weimer (2001) was adopted to specify the pattern of the ionospheric convection. The prescriptions of the upward propagating diurnal and semi diurnal tides are taken from the Global Scale Wave Model (GSWM) (Hagan \& Forbes 2002).

To investigate the response of the thermosphere to 
varying IMF, five TIEGCM simulations for IMF $\left(B_{y} B_{z}\right)$ values of $(-3.2,0.0),(+3.2,0.0),(0.0,-2.0),(0.0,+2.0)$, and $(0.0,0.0) \mathrm{nT}$ are made. The magnitudes of the nonzero reference values of $B_{y}$ and $B_{z}$, that is, $3.2 \mathrm{nT}$ and $2.0 \mathrm{nT}$, are their respective root-mean-square values for the temporally smoothed data set analyzed by Richmond et al. (2003). A 2-min time step is used for the entire simulation, and linear interpolations of input values are made at a given time step. The TIEGCM history is recorded hourly for the period that we studied.

\section{POTENTIAL VORTICITY EQUATION}

A large-scale motion in lower atmosphere below the mesosphere has a synoptic time scale and thus is nearly in an adiabatic and non-friction processes. Therefore, the contour of the potential vorticity on the isentrope surface is nearly material contour and the potential vorticity is conserved along with the isentrope surface. Thus, an analysis of the potential vorticity on the isentrope surface is a useful tool for measuring the flow of air.

Unlike below the mesosphere, since the large-scale motion in the thermosphere is in a diabatic process having sources and sinks, the contour of the potential vorticity on the isentrope surface in the thermosphere is no longer material contour. Moreover, the potential vorticity is not conserved along with the isentrope because the molecular diffusion in the thermosphere is so strong and the time scale of the potential vorticity is so short. In the thermosphere, thus, the potential vorticity itself has no meaning for study of the thermospheric dynamics.

A term analysis of the potential vorticity equation, however, provides a quantitative insight into the contribution of the momentum forcing and the heating to the high-latitude lower thermospheric dynamics, because this equation describes the terms that derive the change of the potential vorticity. The potential vorticity equation can be derived from vorticity equation and is given as (Pedlosky 1979)

$$
\frac{D \Pi}{D t}=\frac{\omega_{a} \cdot \nabla \Psi}{\rho}+\frac{\nabla \lambda \cdot \nabla \times\left(F_{V}+F_{I}\right)}{\rho}-\frac{\nabla \lambda}{\rho} \cdot \nabla\left(\frac{1}{\rho}\right) \times \nabla P
$$

(a)

(b)

(c)

where $\Pi$ is the Ertel's potential vorticity on the isobaric surface. $\omega_{a}$ is the vertical component of the absolute vorticity, $\rho$ is atmospheric mass density. $\lambda$ is some scale fluid property and could be the potential temperature $(\theta)$ or $\mathrm{ms} / \mathrm{R}$, where $m$ is the atmospheric molecular mass, $s$ is the entropy, and $R$ is the universal gas constant. $\Psi$ is defined as $D \lambda / D t$ and is associated the net heat. In Eq. (1), $P$ is pressure, and $F_{V}$ and $F_{I}$ are the viscous and ion drag forces, respectively. The time rate of change of the potential vorticity is determined by the following terms on the right hand side of the Eq. (1): (a) heating term, (b) momentum forcing term associated with the viscous and ion drag forces, and (c) term associated with the pressure gradient.

The individual terms in units of $\mathrm{m}^{2} \mathrm{~kg}^{-1} \mathrm{Ks}^{-2}$ at all model grid points for each hour of universal time are obtained by using the potential vorticity Eq. (1) with outputs of the model, where vertical and horizontal finite differencings are performed to calculate terms at a given altitude for each universal time. We then carry out an averaging for 24 hours of each potential vorticity forcing terms. The resultant forcing terms with respect to different altitudes can be then mapped out over magnetic latitude and magnetic local time.

\section{RESULTS}

In order to examine closely how the potential vorticity forcing and heating terms are influenced by the IMF, we consider the difference potential vorticity forcing and heating terms, obtained by subtracting values with zero IMF from those with non-zero IMF conditions.

Fig. 1 shows the calculated distribution of difference forcing term, which is associated with ion-drag and viscosity, contributing to the change of the potential vorticity at 195, 177, 160, 146, 134, 125, 117, 111, and $106 \mathrm{~km}$ altitudes over the southern hemisphere in the poleward latitude $-50^{\circ}$ for IMF $\left(B_{y}, B_{z}\right)$ values of $(-3.2,0.0),(3.2,0.0)$, $(0.0,-2.0)$, and $(0.0,2.0) \mathrm{nT}$. These projections are as if one were looking up on the thermosphere from below. Solid and dotted lines represent positive and negative values, respectively. The minimum and maximum values are indicated at the lower corner of each plot. The distributions of the forcing terms at 195, 177, and $160 \mathrm{~km}$ altitudes are shown with contour interval of $50 \mathrm{~m}^{2} \mathrm{~kg}^{-1} \mathrm{Ks}^{-2}$. They are shown with contour interval of $10 \mathrm{~m}^{2} \mathrm{~kg}^{-1} \mathrm{Ks}^{-2}$ at 146, 134, $125 \mathrm{~km}$ altitudes, and with contour interval of $0.2 \mathrm{~m}^{2} \mathrm{~kg}$ ${ }^{1} \mathrm{Ks}^{-2}$ at 117,111 , and $106 \mathrm{~km}$ altitudes.

For negative IMF $B_{y}$, at $195 \mathrm{~km}$ strong positive difference forcing occurs in the poleward latitude $-75^{\circ}$ (near polar region) with the maximum value of $1038 \mathrm{~m}^{2} \mathrm{~kg}^{-1} \mathrm{Ks}^{-2}$. There is also negative difference forcing region at $-65^{\circ} \sim-75^{\circ}$ latitude (near auroral region) with the minimum value 

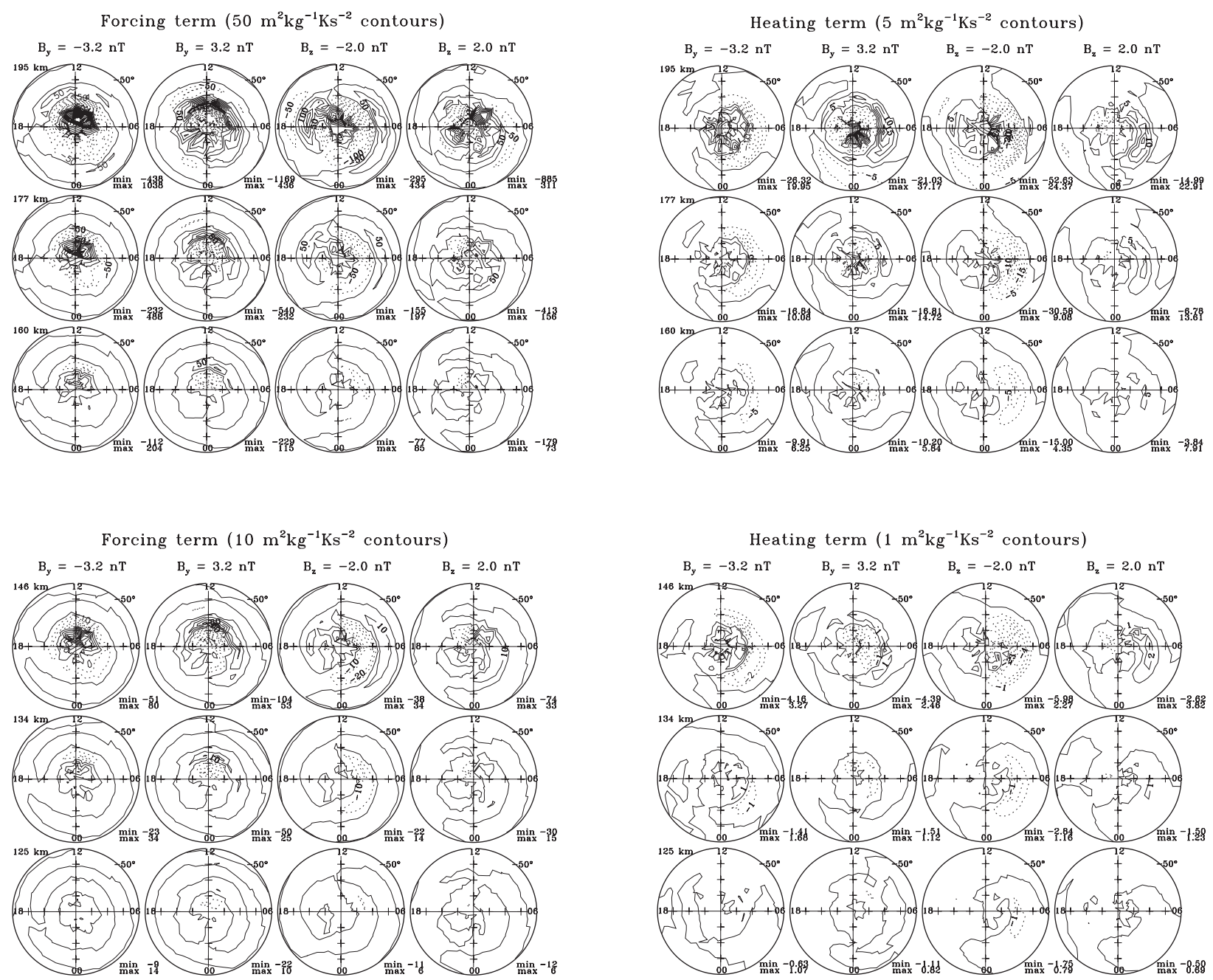

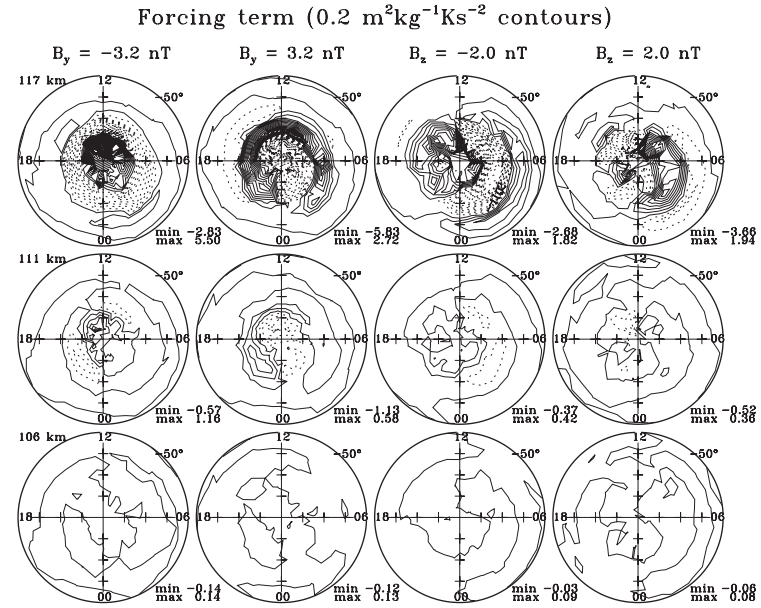

Fig. 1. Distribution of difference forcing term contributing to the change of the potential vorticity at 195, 177, 160,146, 134, 125, 117, 111, and 106 $\mathrm{km}$ for interplanetary magnetic field (IMF) $\left(B_{y}, B_{z}\right)$ values of $(-3.2,0.0),(3.2$, $0.0),(0.0,-2.0)$, and $(0.0,2.0) \mathrm{nT}$. These are obtained by subtracting values with zero IMF from those with non-zero IMF conditions.

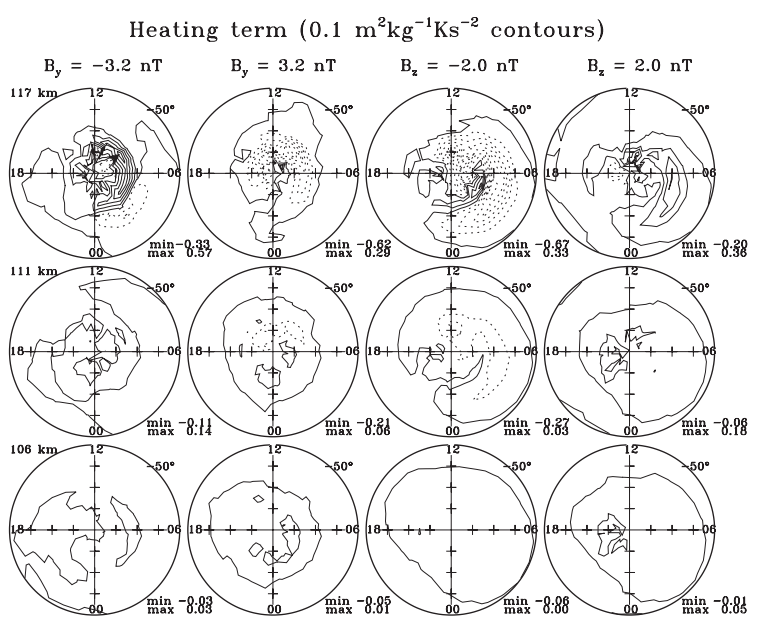

Fig. 2. Distribution of difference heating term contributing to the change of the potential vorticity at 195, 177, 160, 146, 134, 125, 117, 111 , and $106 \mathrm{~km}$ for interplanetary magnetic field (IMF) $\left(B_{y}, B_{z}\right)$ values of $(-3.2,0.0),(3.2,0.0),(0.0,-2.0)$, and $(0.0,2.0) n T$. These are obtained by subtracting values with zero IMF from those with non-zero IMF conditions. 
of $-438 \mathrm{~m}^{2} \mathrm{~kg}^{-1} \mathrm{Ks}^{-2}$. For positive IMF $B_{y^{\prime}}$, the distribution is similar but the sign is opposite with that for negative $B_{y}$ at roughly the same place. For negative IMF $B_{z}$ condition, at $195 \mathrm{~km}$ there are positive difference forcing regions on the dusk with the maximum of $434 \mathrm{~m}^{2} \mathrm{~kg}^{-1} \mathrm{Ks}^{-2}$ and negative difference forcing regions on the dawn sides with the minimum of $-295 \mathrm{~m}^{2} \mathrm{~kg}^{-1} \mathrm{Ks}^{-2}$, respectively. When positive IMF $B_{z}$ condition, the sign is opposite with that for negative $B_{z}$ at roughly the same place with the minimum of $-885 \mathrm{~m}^{2} \mathrm{~kg}^{-1} \mathrm{Ks}^{-2}$ and the maximum of $311 \mathrm{~m}^{2} \mathrm{~kg}^{-1} \mathrm{Ks}^{-2}$. It is evident that the difference forcing is more significant for strong IMF $B_{y}$ condition, and the difference forcings in the polar cap are larger by a factor of about 2 than those in the auroral region. It is obvious that the magnitude of the difference forcing decreases rapidly with descending altitudes.

Fig. 2 shows the calculated distribution of difference heating term contributing to the change of the potential vorticity at 195, 177, 160, 146, 134, 125, 117, 111, and $106 \mathrm{~km}$ altitudes over the southern hemisphere for IMF $\left(B_{y}, B_{z}\right)$ values of $(-3.2,0.0),(3.2,0.0),(0.0,-2.0)$, and $(0.0$, 2.0) nT. The distributions of the forcing terms at 195, 177 , and $160 \mathrm{~km}$ altitudes are shown with contour interval of $5 \mathrm{~m}^{2} \mathrm{~kg}^{-1} \mathrm{Ks}^{-2}$. They are shown with contour interval of 1 $\mathrm{m}^{2} \mathrm{~kg}^{-1} \mathrm{Ks}^{-2}$ at $146,134,125 \mathrm{~km}$ altitudes, and with contour interval of $0.1 \mathrm{~m}^{2} \mathrm{~kg}^{-1} \mathrm{Ks}^{-2}$ at 117,111 , and $106 \mathrm{~km}$ altitudes.

For negative IMF $B_{y^{2}}$, at $195 \mathrm{~km}$ positive difference heating occurs in the poleward latitude $-75^{\circ}$ with the maximum value of $19.95 \mathrm{~m}^{2} \mathrm{~kg}^{-1} \mathrm{Ks}^{-2}$. There is negative difference heating region in the morning auroral region around $-65^{\circ} \sim-75^{\circ}$ latitude with the minimum value of $-26.32 \mathrm{~m}^{2} \mathrm{~kg}^{-1} \mathrm{Ks}^{-2}$. For positive IMF $B_{y^{\prime}}$, the distribution is similar but the sign is opposite with that for negative $B_{y}$ at roughly the same place. For negative IMF $B_{z}$ condition, at $195 \mathrm{~km}$ there are positive difference heating regions on the dusk including the polar cap with the maximum of $24.37 \mathrm{~m}^{2} \mathrm{~kg}^{-1} \mathrm{Ks}^{-2}$ and negative difference heating regions in the auroral region on the dawn sides with the minimum of $-52.63 \mathrm{~m}^{2} \mathrm{~kg}^{-1} \mathrm{Ks}^{-2}$, respectively. When positive IMF $B_{z}$ condition, the sign is opposite with that for negative $B_{z}$ at roughly the same place with the minimum of $-14.99 \mathrm{~m}^{2} \mathrm{~kg}^{-1} \mathrm{Ks}^{-2}$ and the maximum of $22.91 \mathrm{~m}^{2} \mathrm{~kg}^{-1} \mathrm{Ks}^{-2}$. It is evident that the difference heating is the most significant for negative IMF $B_{z}$ condition, and the difference heatings in the auroral region are larger by a factor of about 1.5 than those in the polar cap region. It is obvious that the magnitude of the difference heating decreases rapidly with descending altitudes. Although not shown here, term (c) in the potential vorticity Eq. (1) is much smaller than the forcing term (a) or the heating term (c).
Indeed, the absolute values of difference term (c) associated with the pressure gradient are less than $5 \mathrm{~m}^{2} \mathrm{~kg}^{-1} \mathrm{Ks}^{-2}$ at $195 \mathrm{~km}$ for all IMF conditions.

To see relative contributions of the forcing and heating to the high-latitude lower thermospheric dynamics for different IMF conditions and with altitudes, we examine a forcing-to-heating ratio. Fig. 3 shows this ratio with altitudes for different IMF conditions. Solid-black and dotted-grey bars represent forcing-to-heating ratio for positive (or maximum) and negative (or minimum) values from Figs. 1 and 2, respectively. For negative $B_{y}$ condition shown in Fig. 3a, the solid-black and dotted-grey bars represent forcing-to-heating ratio for in the polar cap and in the auroral region, respectively. For positive $B_{y}$ condition (Fig. $3 \mathrm{~b}$ ), the solid-black and dotted-grey bars represent forcing-to-heating ratio for in the auroral region and in the polar cap region, respectively. One can see that the ratio is more than 2 with maximum 65.6 at $195 \mathrm{~km}$ for positive $B_{y}$ condition, indicating that the contribution of the forcing to the high-latitude lower thermospheric dynamics is stronger than the contribution of the heating to it. The forcing-to-heating ratio is much larger by a factor of 1.2 5.5 in the polar cap region than in the auroral region above $125 \mathrm{~km}$ altitude. It is obvious that the magnitude of the ratio decreases rapidly with descending altitudes. Especially, the ratio in the polar cap region decreases more rapidly with descending altitudes than in the auroral region. For negative $B_{z}$ condition shown in Fig. 3c, the solid-black and dotted-grey bars represent forcing-to-heating ratios in the evening auroral region including polar cap and in the morning auroral region, respectively. One can see that the ratio is more than 1.5 with maximum 21.7 at $177 \mathrm{~km}$ except at $106 \mathrm{~km}$ in the morning auroral region, indicating that the contribution of the forcing to the high-latitude lower thermospheric dynamics is stronger than the contribution of the heating to it. It is shown that the ratio in the evening auroral region including the polar cap is larger by a factor of 1.2 10 than in the morning auroral region and that the ratio at all altitudes except for $111 \mathrm{~km}$ is smaller by a factor of about 0.3 than for other IMF conditions. For positive $B_{z}$ condition (Fig. 3d), the solid-black and dotted-grey bars represent forcing-to-heating ratios in the morning auroral region and in the evening auroral region including polar cap, respectively. It is shown that the ratio in the evening auroral region including the polar cap is larger by a factor of 1.5 5 than in the morning auroral region. One can see again the forcing-to-heating ratio decreases rapidly with descending altitudes.

From Fig. 3, it is evident that the contribution of the 


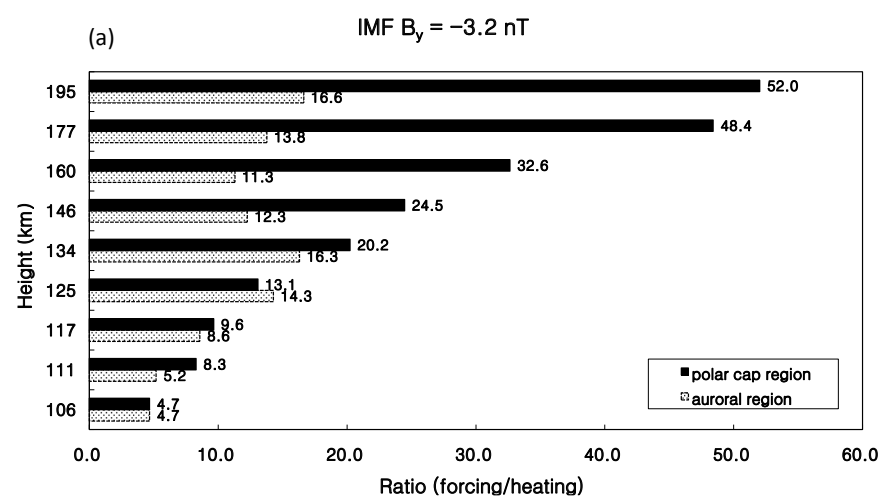

(b)

IMF $B_{\mathrm{y}}=3.2 \mathrm{nT}$

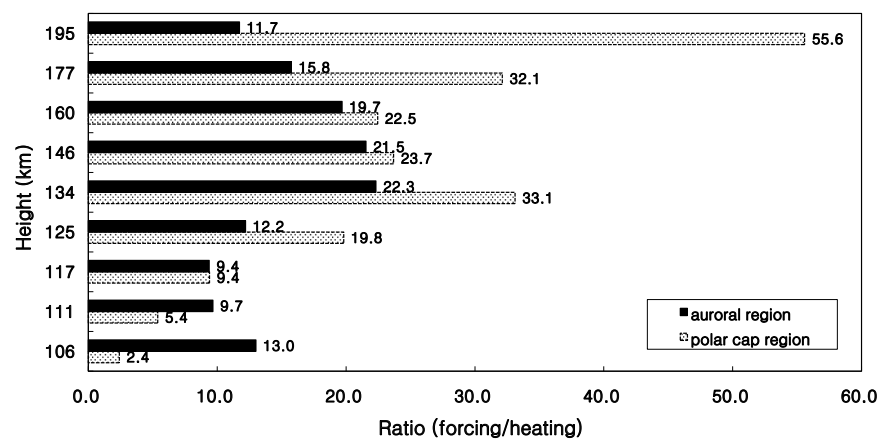

(c)

IMF $B_{2}=-2.0 n T$

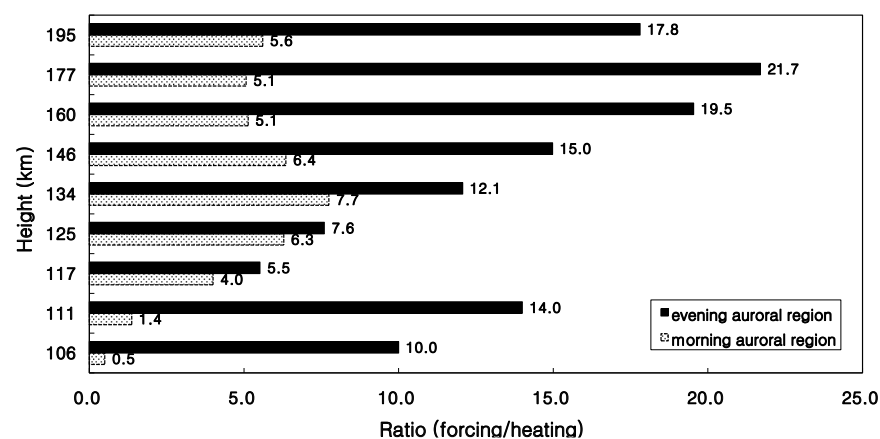

(d) $\quad$ IMF $B_{z}=2.0 \mathrm{nT}$

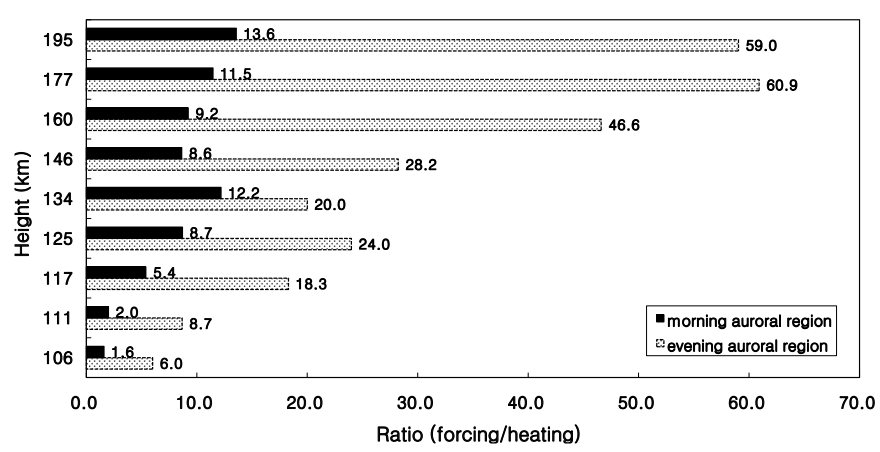

Fig. 3. The difference forcing-to-heating ratio at $195,177,160,146,134,125,117,111$, and $106 \mathrm{~km}$ for interplanetary magnetic field (IMF) $\left(B_{y}, B_{z}\right)$ values of $(a)(-3.2,0.0)$, (b) $(3.2,0.0)$, (c) $(0.0,-2.0)$, and (d) $(0.0,2.0) n T$. These ratio are obtained from the forcing term by dividing the heating term. 
forcing to the high-latitude lower thermospheric dynamics is stronger than the contribution of the heating to it. Especially, it is obvious that the contribution of the forcing is much larger at higher altitude than at lower altitude and in the polar cap region than in the auroral region for negative and positive IMF $B_{y}$ conditions. The relative contribution of the forcing in the auroral region for negative $B_{z}$ condition is the lowest among the different IMF conditions.

\section{CONCLUSIONS}

In this paper, we first present the relative contributions of the momentum forcing and the heating to the highlatitude lower thermospheric dynamics depending on the IMF and altitude. For this study we attempted a "term analysis of the potential vorticity equation" for the highlatitude neutral wind field in the lower thermosphere during the southern summertime for different IMF conditions by using NCAR-TIEGCM.

By considering the difference potential vorticity forcing and heating terms, obtained by subtracting values with zero IMF from those with non-zero IMF, we can examine closely how the potential vorticity forcing and heating terms are influenced by the IMF. The difference forcing is more significant for strong IMF $B_{y}$ condition than for strong IMF $B_{z}$ condition. For negative or positive $B_{y}$ conditions, the difference forcings in the polar cap are larger by a factor of about 2 than those in the auroral region. The magnitude of the difference forcing decreases rapidly with descending altitudes. The difference heating is the most significant for negative IMF $B_{z}$ condition, and the difference heatings in the auroral region are larger by a factor of about 1.5 than those in the polar cap region. The magnitude of the difference heating decreases rapidly with descending altitudes.

It is confirmed that forcing-to-heating ratio is large, indicating that the contribution of the forcing to the high-latitude lower thermospheric dynamics is stronger than the contribution of the heating to it and eventually drag from convecting ions is generally more important than Joule heating for generating dynamical energy in the high-latitude lower thermosphere. Especially, it is obvious that the forcing-to-heating ratio is much larger in the polar cap region than in the auroral region and at higher altitude than at lower altitude, indicating that the contribution of the forcing to the dynamics is much larger in the polar cap region than in the auroral region and at higher altitude than at lower altitude. It is evident that when $B_{z}$ is negative condition the contribution of the forcing is the lowest and the contribution of the heating is the highest among the different IMF conditions.

We have presented here only an analysis of the relative contributions of the momentum forcing and the heating to the high-latitude lower thermospheric dynamics. A future study will be devoted to investigating the available energy budget in the high-latitude lower thermosphere.

\section{ACKNOWLEDGMENTS}

This work was supported by the "Development of Korean Space Weather Center", the project of KASI, the KASI basic research fund, and the Korea Research Foundation Grant (KRF-2005-070-C00059).

\section{REFERENCES}

Foster, J. C., Holt, J. M., Musgrove, R. G., \& Evans, D. S. 1986, in SolarWind-Magnetosphere Coupling, eds. Y. Kamide \& J. A. Slavin (Tokyo: Terra Scientific Publishing Company), p. 477

Hagan, M. E. \& Forbes, J. M. 2002, JGRD, 107, 4754, doi: $10.1029 / 2001 J D 001236$

Heppner, J. P. 1972, JGR, 77, 4877, doi: 10.1029/JA077i025p 04877

Heppner, J. P. \& Maynard, N. C. 1987, JGR, 92, 4467, doi: 10.1029/JA092iA05p04467

Hernandez, G., McCormac, F. G., \& Smith, R. W. 1991, JGR, 96, 5777, doi: 10.1029/90JA02458

Killeen, T. L., Hays, P. B., Heelis, R. A., Hanson, W. B., \& Spencer, N. W. 1985, GeoRL, 12, 159, doi: 10.1029/ GL012i004p00159

Killeen, T. L., Won, Y. I., Niciejewski, R. J., \& Burns, A. G. 1995, JGRA, 100, 21327, doi: 10.1029/95JA01208

Kwak, Y. S., Ahn, B. H., \& Kim, K. H. 2008a, JASS, 25, 415

Kwak, Y. S., Lee, J. J., Ahn, B. H., Hwang, J., Kim, K. H., \& Cho, K. S. 2008b, JASS, 25, 405

Kwak, Y. S. \& Richmond, A. D. 2007, JGR, 112, A01306, doi: 10.1029/2006JA011910

Kwak, Y. S., Richmond, A. D., \& Roble, R. G. 2007, JGR, 112, A06316, doi: 10.1029/2006JA012208

Maeda, S., Fuller-Rowell, T. J., \& Evans, D. S. 1989, JGRA, 94, 16869, doi: 10.1029/JA094iA12p16869

McCormac, F. G. \& Smith, R. W. 1984, GeoRL, 11, 935, doi: 10.1029/GL011i009p00935

McCormac, F. G., Killeen, T. L., Gombosi, E., Hays, P. B., \& Spencer, N. W. 1985, GeoRL, 12, 155, doi: 10.1029/ 


\section{GL012i004p00155}

McCormac, F. G., Killeen, T. L., \& Thayer, J. P. 1991, JGR, 96, 115, doi: 10.1029/90JA01996

McHarg, M., Chun, F., Knipp, D., Lu, G., Emery, B. A., \& Ridley, A. 2005, JGR, 110, A08309, doi: 10.1029/2004JA010949

Meriwether, J. W. \& Shih, P. 1987, AnGeo, 5A, 329

Niciejewski, R. J., Killeen, T. L., Johnson, R. M., \& Thayer, J. P., 1992, AdSpR, 12, 215, doi: 10.1016/0273-1177(92)90058-6

Niciejewski, R. J., Killeen, T. L., \&Won, Y. 1994, JATP, 56, 285

Pedlosky, J. 1979, in Geophysical Fluid Dynamics, ed. J. Pedlosky (New York: Springer-Verlag), p.624

Rees, D. \& Fuller-Rowell, T. J. 1989, RSPTA, 328, 139

Rees, D. \& Fuller-Rowell, T. J. 1990, AdSpR, 10, 197, doi: 10.1016/0273-1177(90)90254-W

Richmond, A. D., Lathuillere, C., \& Vennerstroem, S. 2003, JGRA, 108, 1066, doi: 10.1029/2002JA009493
Richmond, A. D., Ridley, E. C., \& Roble, R. G. 1992, GeoRL, 19, 601, doi: 10.1029/92GL00401

Ruohoniemi, J. M. \& Greenwald, R. A. 1996, JGRA, 101, 21743, doi: 10.1029/96JA01584

Sica, R. J., Hernandez, G., Emery, B. A., Roble, R. G., Smith, R. W., \& Rees, M. H., 1989, JGRA, 94, 11921, doi: 10.1029/ JA094iA09p11921

Thayer, J. P., Killeen, T. L., McCormac, F. G., Tschan, C. R., Ponthieu, J. J., \& Spencer, N. W. 1987, AnGeo, 5A, 363

Weimer, D. R. 1995, JGRA, 100, 19595, doi: 10.1029/95JA01755 Weimer, D. R. 2001, JGRA, 106, 407, doi: 10.1029/2000JA000604 Won, Y. 1994, PhD Thesis, University of Michigan

Zhang, X. X., Wang, C., Chen, Y., Wang, Y. L., Tan, A., Wu, T. S., Germany, G. A., \& Wang, W. 2005, JGR, 110, A12208, doi: 10.1029/2005JA011222 